FEDERAL RESERVE BANK OF SAN FRANCISCO

WORKING PAPER SERIES

\title{
Clouded in Uncertainty: Pursuing Financial Stability with Monetary Policy
}

\author{
Sylvain Leduc \\ Federal Reserve Bank of San Francisco \\ January 2021 \\ Working Paper 2021-03 \\ https://www.frbsf.org/economic-research/publications/working-papers/2021/03/
}

\section{Suggested citation: \\ Leduc, Sylvain. "Clouded in Uncertainty: Pursuing Financial Stability with Monetary \\ Policy," Federal Reserve Bank of San Francisco Working Paper 2021-03. \\ https://doi.org/10.24148/wp2021-03}

The views in this paper are solely the responsibility of the authors and should not be interpreted as reflecting the views of the Federal Reserve Bank of San Francisco or the Board of Governors of the Federal Reserve System. 


\title{
Clouded in Uncertainty: Pursuing Financial Stability with Monetary Policy
}

\author{
Sylvain Leduc ${ }^{1}$ \\ Federal Reserve Bank of San Francisco
}

November 17, 2020

\section{Introduction}

The global financial crisis and ensuing Great Recession were watershed moments for macroeconomics and monetary policy in particular. They led to a profound rethinking of the role of financial stability in monetary policy and raised doubts around the idea that monetary policymakers could simply look at financial stability with "benign neglect," concentrating on the conventional objectives of price and output gap stability and mopping up the effects of crises if they arose. In addition, the past 10 years have seen a growing interest in whether macroprudential policies can properly address financial stability risks and lift that burden from monetary policymakers' shoulders.

Now that more than a decade has passed since the start of the global financial crisis, it is appropriate to take stock of the knowledge we gained during that time regarding the nexus between monetary policy and financial stability. This assessment is necessary and timely given the pandemic-driven economic collapse during the spring of 2020, which led the Federal Reserve to buy additional U.S. Treasury and agency mortgage-backed securities and to re-establish several lending facilities first introduced during the global financial crisis to help stabilize financial markets. With a highly leveraged non-financial corporate sector and reliance on shortterm funding, restoring smooth markets functioning became critical to avoiding tail events.

\footnotetext{
${ }^{1}$ Prepared for the Max Bell School of Public Policy's conference Choosing the Right Target. I'd like to thank Òscar Jordà, Jean-Marc Natal, and Jean-François Rouillard for useful comments and conversations. Email: sylvain.leduc@sf.frb.org. The views expressed here are my own and do not reflect those of the Federal Reserve Bank of San Francisco or the Federal Reserve System.
} 
Based on theory, I argue that introducing financial stability as an objective of monetary policy is fully consistent with flexible inflation targeting regimes. Once financial market imperfections are introduced into a macroeconomic framework, financial stability objectives are compatible with a flexible inflation targeting framework. In this case, the optimal monetary policy at times may need to "lean against the wind," that is, be more restrictive than would otherwise be the case to simply achieve price stability. However, from a practical policy perspective, I also argue that the costs and benefits of leaning against the wind are too uncertain to calibrate monetary policy with any reasonable degree of comfort. How these costs and benefits respond to changes in interest rates is highly uncertain, not only with respect to their magnitudes but also the direction of change. Given that monetary policy impacts the overall economy, the costs of miscalibrating policy are likely to be high. Standard uncertainty arguments would thus call to reduce the weight of financial stability in monetary policy decisions. If anything, the tradeoff of leaning against the wind looks fairly unfavorable for interest rate policy, suggesting that other policy tools would likely be better suited to address financial vulnerabilities. In particular, the empirical evidence suggests that macroprudential policies have proven effective at mitigating financial vulnerabilities in several countries. They also have the advantage of being more targeted and should be used first; however, the uncertainty regarding their calibration and efficacy would dictate a gradual approach in their implementation.

The role of financial stability in monetary policy is particularly relevant in the current low interest rate environment, which may incentivize risk-taking and increase financial vulnerabilities. Cyclically accommodative policies are not solely to blame for this state of affairs; declining trends for productivity and labor force growth have also contributed to low neutral rates of interest consistent with price and output gap stability around the world. In this environment, the probability that monetary policy could be constrained by the effective lower bound (ELB) in the future is substantially higher than a decade ago. While unconventional policies, such as forward guidance and quantitative easing, can provide policy accommodation at the ELB, it remains debatable whether they can fully compensate for the shortcomings in central banks' conventional policy instruments. With long-term interest rates also being very low, there is less scope for unconventional policy accommodation. Thus, several central banks are currently revisiting the idea of using so-called makeup strategies. Central banks would communicate their intentions to make up previous downward misses on inflation, for instance, through a policy 
stance consistent with above-target inflation in the future. By generating expectations of a "lower for longer" policy at the ELB, makeup strategies can, in principle, raise inflation expectations, lower the real interest rate, and boost economic activity and inflation. However, keeping the policy rate lower for longer can also lead to a buildup of financial vulnerabilities, compressing risk premia and increasing leverage, among others.

Another important channel of transmission that interacts with monetary policy and can impact financial vulnerabilities is international capital flows. This channel has been particularly important for emerging market economies over the years, inducing several balance of payments crises. As capital flows have grown in importance, they have also impacted larger advanced economies, as the "conundrum" in the mid-2000s emphasizes. International capital flows can have significant effects on borrowing costs and the exchange rate, thus impacting indebtedness, domestic demand, and competitiveness, and ultimately output gaps and inflation. International capital inflows into domestic housing markets have often been pinpointed as important factors behind recent credit and housing booms in several small open advanced economies. This international dimension adds another wrinkle to how flexible inflation targeting regimes should weigh traditional policy objectives against other objectives related to the financial cycle. With high capital mobility, it's important to examine conditions under which monetary policy should raise the policy rate to contain the impact of a capital inflow on demand and inflation at the cost of a loss of economic activity. I discuss simple economies where, in the absence of macroprudential policies, this response intuitively depends on the sensitivity of the economy to exchange rate movements and the degree of openness. Still, the experience that emerging market economies have had with managing the impact of capital inflows is also instructive and suggests that macroprudential policies can be useful in addressing financial vulnerabilities induced by capital inflows.

Overall, given the costly tradeoff between financial stability and conventional policy objectives when leaning against the wind, macroprudential policies should become the first line of defense to contain financial stability risks. Even though we still lack experience designing and calibrating macroprudential policies, they have the benefit of being more targeted relative to monetary policies that lean against the wind. The recent Canadian experience suggests that well-tailored macroprudential policies can be effective in reducing financial stability risks, for instance, in 
bringing about a more resilient allocation of mortgage credit. Nevertheless, in practice, one possible risk of relying on macroprudential policies is that their governance in several countries makes policymakers prone to be biased toward inaction. As such, designing institutions with clear financial stability mandates and lines of accountability is crucial to make macroprudential policies effective not only in theory but also in practice.

\section{Monetary Policy, Procyclicality, and Inefficiencies}

One challenge in incorporating financial market stabilization into monetary policy is that finance is highly procyclical and experiences long cycles. Financial intermediation can facilitate the allocation of resources toward productive use and can help households and firms smooth the impact of unforeseen events. However, because of its procyclicality, finance can also amplify the business cycle and lead to an inefficient allocation of resources, as happened with the large housing stock in the U.S. "sand states" in the wake of the crisis.

How should monetary policy be conducted when finance is necessary but is also a potential source of inefficient procyclicality? Should policymakers concentrate on price stability, or should they lean against the wind to mitigate the rise in asset prices, credit, and leverage to mute the procyclical responses to economic news? Even abstracting from financial crises, standard macro-finance models prescribe that the optimal monetary policy should lean against the wind to some extent. This can occur, for instance, in environments in which firms need external funding to finance projects and lenders cannot costlessly observe the activity of borrowers and the outcome of their investment projects. The premium above the risk-free rate that borrowers need to pay to borrow funds partly depends on their net worth. During good economic times, borrowers' net worth increases and risk premia fall, in turn leading to an increase in credit and more projects being financed, which ultimately boosts economic activity further. Thus, the financial market imperfections underlying this environment give rise to a feedback loop that amplifies the response of the economy to shocks. The resulting boom in economic activity is partly inefficient when compared to an economy without financial market imperfections. Underlying this feedback loop is a pecuniary externality that leads to overborrowing, because borrowers do not internalize that more borrowing boosts asset prices and net worth, thus making additional credit easier to obtain. 
The optimal monetary policy in this environment deviates from price stability and takes into account the impact of overborrowing and leverage in determining the policy stance (see Leduc and Natal, 2017). During good economic times, policymakers adopt a more restrictive policy stance than would be prescribed under price stability to contain increases in borrowing, leverage, and asset prices, thus muting the effects of the feedback loop and aligning the economic responses closer to their efficient levels. Importantly, by leaning against the wind in a systematic manner, the optimal monetary policy can affect the expectations of households, banks, and firms and influence their behavior, mitigating overborrowing and the misallocation of resources.

How much to lean against the wind still needs to be determined. Even in this simple environment, the degree of lean depends on the level of efficient output fluctuations and the associated output gap, which are clearly difficult objects to determine in practice. Needless to say, parsing out efficient from inefficient fluctuations is plagued by a high degree of uncertainty. However, in this simple framework, the optimal monetary policy can be reasonably well approximated by a so-called speed limit interest rate rule. The rule determines the level of the policy rate as a function of inflation movements from target and the growth rate of output, as well as the growth rates of financial variables such as leverage, asset prices, and credit growth. Thus, an advantage of this rule is that it avoids setting the policy stance based on the efficient levels of output and financial variables and is thus more practical for policymakers. By focusing on growth rates, the rule is a good approximation to the optimal policy, since, under commitment, the optimal policy is history dependent.

\section{Open Economy Dimensions of Leaning Against the Wind}

Financial markets can also lead to inefficient allocations through international channels. Given the increase in financial and trade integration over the past 40 years, international factors can have a substantial impact on domestic variables and lead to challenging policy decisions.

For instance, the international spillovers of the Federal Reserve's unconventional monetary policies through capital inflows and currency appreciations in other economies (see, for instance, Neely, 2015; Glick and Leduc, 2012, 2018; Rogers, Scotti, and Wright, 2018) presented policymakers in those countries with difficult tradeoffs, particularly in emerging market economies (see Bruno and Shin, 2012, for a theoretical model of the risk-taking channel in an international context). On the one hand, capital inflows increased concerns about credit-fueled 
growth and worsening financial vulnerabilities. Absent macroprudential policies, a monetary policy tightening could be warranted as a result. On the other hand, appreciating currencies in emerging markets caused pressures on the export sector and raised concerns about loss of competitiveness. Tightening monetary policy in this context could end up exacerbating the currency appreciation. Policymakers in emerging market economies have been vocal about the impact of these spillovers. For instance, Raghuram Rajan, then-governor of the Reserve Bank of India, called for central banks in advanced economies to be cognizant of the costs of their policies to other countries (Rajan, 2014), as capital inflows can contribute to heightening financial vulnerabilities. Similarly, Luiz Pereira da Silva, then-deputy governor of the Banco Central do Brasil, referred to the experiences of emerging markets in the wake of U.S. quantitative easing as a "sudden flood" of liquidity, and emphasized the associated pressures on domestic asset prices, credit markets, and inflation (Luiz Pereira da Silva, 2013). Both policymakers also highlighted the importance of greater policy coordination.

Traditional open economy models with complete financial markets provide little guidance to policymakers facing these difficult tradeoffs. For instance, to the extent that a current account deficit raises the natural rate of interest (i.e., the rate under flexible prices), policymakers should respond to a capital inflow with a more restrictive policy stance (Obstfeld and Rogoff, 2010). In other words, focusing on price stability is sufficient. However, the natural allocation may be a poor guide when financial markets are more realistic, as the previous section emphasized. In the case of an open economy with incomplete financial markets, the natural allocation can bring about excessive borrowing and lending compared to an efficient one, for instance, due to the presence of pecuniary externalities associated with inefficient exchange rate movements (Farhi and Werning, 2016; Corsetti, Dedola, and Leduc, 2010, 2020).

When open economies operate under incomplete international financial markets, the optimal policy depends not only on inflation and the output gap, but also on international factors, such as currency misalignments and demand imbalances across countries (see Corsetti, Dedola, and Leduc, 2010, 2020, for details). Facing an inefficient capital inflow that appreciates the currency and boosts demand, the optimal policy depends on the degree of expenditure switching from exchange rate movements. When the degree of exchange rate pass-through is low, implying a small expenditure switching effect, policymakers should adopt a more restrictive stance than 
price stability would dictate to stem the increase in demand, despite the additional pressure on the currency to appreciate. Given the lack of expenditure switching effects, the impact of the appreciation on the competitiveness of the export sector and the output gap is small, and policymakers can thus concentrate on the impact of capital flows on demand. In contrast, for economies with a high exchange rate pass-through and a large expenditure switching effect, policymakers should adopt an easier stance than under price stability to mitigate the impact of the capital inflow on competitiveness and the output gap.

To obtain stark policy prescriptions, frameworks such as the one just described remain highly stylized and abstract from several financial market features that impact financial vulnerabilities and would need to be taken into account when calibrating the policy stance in practice. As a result, they very much remain imperfect guides for policymakers. Importantly, they do not take into account the possibility that financial vulnerabilities may ultimately lead to full-blown crises.

\section{Financial Crises}

Because they occur infrequently, financial crises are notoriously difficult to predict. However, research since the global financial crisis has uncovered a few factors that consistently emerge as better predictors of these events. Schularick and Taylor (2012) emphasize leverage in the banking sector as a crucial vulnerability leading up to financial meltdowns. Using data on advanced and emerging market economies, Gourinchas and Obstfeld (2012) find that a sharply appreciating currency, in addition to a rise in leverage, are key determinants of financial crises. These empirical linkages can help policymakers calibrate policy to mitigate the risk of crises down the road.

Woodford (2012) argues that the traditional inflation targeting regime can accommodate financial stability as another welfare objective. In an environment with credit frictions, he introduces a reduced-form relationship dictating that higher leverage increases the probability of a financial crisis. The credit frictions lead some households to be credit constrained, such that marginal utilities of income are not equalized across households, as would be the case in an economy with frictionless financial intermediation. In turn, the discrepancy in marginal utilities corresponds to a credit spread, which lowers aggregate demand. A crisis is modeled as a probability that this spread becomes large, with the probability increasing in the leverage of the financial sector. In this environment, the optimal policy takes the form of a flexible price-level 
target. However, because of the endogenous crisis probability, the optimal price path takes into account the evolution of a financial indicator that captures the expected loss from a financial crisis, in addition to the path of the output gap. When this loss is big, the optimal policy is such that either the price level or output undershoots its equilibrium level or both. In other words, it would be optimal to lean against the wind and delay the return to price stability. Recently, Beaudry (2020) argued in favor of a similar approach in the Canadian context.

More generally, it is useful to organize the effects of leaning against the wind using the following four broad categories (see, for instance, Walsh, 2017). Focusing on an economy in normal times, the welfare loss (or benefit) of leaning against the wind is given by the impact of the policy through four broad channels impacting:

1. current inflation and unemployment rates,

2. the probability of crisis,

3. the expected magnitude of a crisis, if a crisis were to occur, and

4. the probability of exiting a crisis.

As emphasized by Svensson (2017), in practice, policymakers are confronted with quantifying the costs and benefits of using monetary policy for financial stability purposes. For a central bank that attempts to stabilize inflation around a target and unemployment around its natural rate, Svensson (2017) calculates that, under a wide variety of assumptions, the costs largely outweigh the benefits. Intuitively, the more direct costs of leaning against the wind are the loss of current output, higher unemployment rate, and lower inflation rate during normal times when the policy is implemented (the first channel above). Empirically, a large body of evidence documents that a policy tightening significantly raises the unemployment rate and lowers inflation with some lag. Hence, leaning against the wind is typically assumed to generate an initial welfare loss. However, while a priori intuitive, moderating an expansion could still bring benefits if it reduces the distortions and inefficiencies associated with the boom, as previously discussed, but which are not taken into account in Svensson's analysis. Therefore, whether the impact of leaning against the wind in normal times is factored in as a cost or a benefit will depend on modeling features. Given that our understanding of the macro-finance linkages is fairly poor, a great deal of uncertainty clouds empirical estimates of the effects of leaning against the wind on the current state of the economy. 
The impact of a policy tightening on the probability of a crisis, the second channel, is also murky. The best evidence comes from the historical evidence in Schularick and Taylor (2012), who link the crisis probability to real credit growth, with the unconditional probability across 14 countries averaging about 4 percent between 1870 and 2008. Therefore, by reducing real credit growth, leaning against credit growth could lower the probability of a crisis. However, because a policy tightening would reduce both nominal credit growth and inflation, the impact on real credit growth is a priori ambiguous. For instance, Mason and Jayadev (2014) show that movements in nominal income growth and inflation are largely responsible for movements in real debt and the debt-to-income ratio in U.S. data since 1929, what they term "Fisher dynamics." In fact, using a panel of 18 countries from 1975 to 2014, Bauer and Granziera (2017) find that real debt and the debt-to-GDP ratio increase in the short run following an unexpected monetary tightening, while both variables decrease in the medium run. Consistent with the finding in Mason and Jayadev (2014), this partly reflects the fact that nominal debt is largely determined by decisions made in the past, so that it is largely insensitive to change in monetary policy in the short run. However, real debt or debt-to-GDP can increase in the short run through declines in prices and output. Thus, leaning against the wind introduces difficult intertemporal tradeoffs and could certainly trigger events policymakers are trying to avoid in the short run.

Moreover, the evidence suggests that monetary policy needs to be tightened substantially to have a meaningful effect on financial vulnerabilities over time (see, for instance, Musso et al., 2011, or Kiley, 2018). An interesting calculation comes from Jordà, Schularick, and Taylor (2015). They report that, while a policy tightening does reduce mortgage lending and house prices (as ratios to GDP), U.S. monetary policy would have had to be 8 percentage points tighter by the end of 2002 to preemptively contain the house price bubble experienced in the 2000s. In turn, their estimates suggest that the output loss in this case would have been even greater than the loss during the Great Recession. Clearly, costs of this magnitude should give policymakers some pause before they preemptively lean against the wind. Relatedly, Svensson (2017) emphasizes that the costs of a crisis depend on the state of the economy when the crisis hits, which will also hinge on previously implemented policies. By weakening economic activity, leaning against the wind may lead the economy to enter a crisis in a weaker position than if the policy rate had not been raised, deepening the magnitude of a crisis (the third channel). 
The costs and benefits of leaning against the wind also depend on the probability of exiting a crisis (the fourth channel), a channel that Svensson (2017) abstracts from. While there has been little analysis of this channel, Jordà, Schularick, and Taylor (2013) suggest that leaning against the wind can also be beneficial by speeding up the exit from a crisis. For instance, looking at 200 recessions in 14 advanced economies between 1870 and 2008, they find that economies exit more slowly from crisis-triggered recessions when they are preceded by credit-fueled expansions.

To get a sense of the overall cost and benefit of leaning against the wind, one avenue is to use the empirical evidence about the effect of a policy tightening on indicators of indebtedness and then estimate the impact of indebtedness on the magnitude of downturns. While the results in Bauer and Granziera (2017) suggest that the impact of a policy tightening on real debt varies over time, Svensson (2017) assumes that a more restrictive policy stance leads to a decline in real debt based on evidence from the Riksbank for Sweden. Using in turn the evidence in Schularick and Taylor (2012) linking the probability of a crisis to real debt, Svensson calculates the marginal benefit of leaning against the wind and compares it to his calculation for the marginal cost, finding that the policy is very costly in terms of welfare and that the result is robust to several changes in assumptions.

However, an alternative approach is to model the effect of systematically leaning against the wind through its impact on households' and firms' expectations, as was discussed in Sections 2 and 3. Through this systematic approach, monetary policy can alter households' and firms' behavior. Systematically leaning against the wind could therefore be viewed as providing conditions that support financial stability in normal times, even if the overall impact on the probability of a crisis may remain small (Borio and Lowe, 2002, and Juselius et al., 2016). This approach is appealing on methodological grounds, though given the current state of macrofinance models, the results from this strategy are unlikely to be sufficiently robust to different modeling assumptions to provide clear guidance to policymakers in practice. For instance, Gerdrup et al. (2017) examine leaning against the wind in a medium-scale DSGE model in which the probability and severity of a crisis respond to credit growth. In this setup, leaning against the wind is optimal. However, as in Woodford (2012), credit growth has no other effects on the economy, since the model abstracts from financial intermediation or any other financial linkages 
with the macroeconomy. Thus, it doesn't allow for any beneficial effects from credit growth on economic activity. As a result, while the approach captures changes in expectations from systematically leaning against the wind, it remains far from the type of quantitative analysis that can be relied on for policy decisions.

Filardo and Rungcharoenkitkul (2016) follow a similar approach but with the added advantage of trying to capture the slow buildup of financial imbalances over time that we observe empirically (see Drehmann, Borio, and Tsatsaronis, 2012). As a result, they show that there is a role for monetary policy to systematically lean against the wind, such that policy reacts early to the development of imbalances instead of waiting for the signs of a crisis to be more imminent, thus reducing the amplitude of the financial cycle. However, as in Gerdrup et al. (2017), the macrofinance linkages are very stylized, which makes it particularly difficult to assess what portion of the financial buildup is efficient and thus makes the results of any cost-benefit analysis highly uncertain.

Nonetheless, the emphasis they place on the persistence of the financial cycle is crucial. To be useful guides for policymakers, these dynamic macro models need to capture the fact that the business and financial cycles often operate at different frequencies. Adrian et al. (2019) tackle this challenge using a semistructural model of endogenous volatility that is sufficiently flexible to match several key financial facts, including the fact that downside risks increase in the medium term following easy financing conditions. Absent macroprudential policies, policymakers should pay attention to financial conditions when setting the policy stance. However, as others have found in different environments, macroprudential policies can be effective at reducing financial vulnerabilities, thus allowing monetary policy to concentrate on price and output gap stability.

As with the persistence of the financial cycle, determining whether to lean against the wind or not will be highly sensitive to the assumed persistence of output loss following a crisis (the third channel above). A notable feature of several advanced economies post-crisis is that the level of output has suffered a seemingly permanent, or at least very persistent, drop from its pre-crisis level. As shown by Gourio, Kashyap, and Sim (2018), when this feature is taken into account, it is optimal to lean against the wind as long as the crisis is triggered by (inefficient) financial shocks, but not if it is induced by productivity or demand shocks. Of course, sorting out the 
source of the shocks in real time would pose a considerable challenge to policymakers. As such, the additional finding that macroprudential policies are also effective at containing financial risks may be more promising.

All told, I'm led to conclude that models lack several important features of the financial architecture and miss the dynamics of the financial cycle. Thus, they are far too simple to provide practical guidance about whether to lean against the wind or not, let alone about how to calibrate a policy rate increase if policymakers did decide to use monetary policy for financial stability purposes. In addition, the empirical evidence indicates that leaning against the wind can end up making financial vulnerabilities worse in the short run and that a large policy contraction is necessary to reduce them substantially over time. Since monetary policy impacts the overall economy, the costs of miscalibrating are high. As such, using other policies to address financial stability objectives may be more promising.

\section{Prudential Policies}

To achieve the Tinbergen principle of having one instrument per goal, macroprudential tools have been proposed to tackle the procyclicality of finance and thus relieve the pressure on monetary policy to fulfill this role. To address systemic risk to the financial system, Crockett (2000) and Borio et al. (2001) have proposed that macroprudential policies are necessary to complement microprudential policies. Since the financial crisis, these policies have been used much more frequently, particularly ones targeted toward the housing sector, in both advanced and emerging market economies (IMF-FSB-BIS, 2016). Because macroprudential policies have been introduced at different times in different countries, the data provide fertile ground to assess their effectiveness in mitigating the procyclicality of the financial cycle and reducing financial vulnerabilities. Compared to the early 2000s, we have now a better understanding of the effectiveness of macroprudential policies. The list of such policies in practice ranges from the countercyclical capital buffer that could be activated along the cycle, thus adding to "static" capital requirements, to dynamic loan-loss provisioning, sector-specific credit growth limits, and time-varying loan-to-value and debt-to-income ratio caps for loans. In addition, stress tests have become common tools to assess the resilience of the financial system to different risk scenarios. Since emerging market economies have been much more prone to financial crises, they have 
experimented with additional tools, including capital controls of different forms and changes in reserve requirements.

Indeed, Federico, Vegh, and Vueltin (2012) document in a set of 52 countries from 1970 to 2011 that 74 percent of developing economies in their sample used reserve requirements in a countercyclical fashion, while only 35 percent used monetary policy to that end. A reason for pursuing a somewhat acyclical monetary policy is that policymakers fear rapid depreciation if they loosen the policy stance in bad times or an influx of capital and rapid appreciation if they tighten monetary policy in good times. However, some central banks in emerging market economies use reserve requirements as an additional instrument targeted to mitigating credit growth (see, e.g., Montoro and Moreno, 2011). Mimir, Sunel, and Taşking (2013), for instance, document that Turkey increased the required reserve ratio from 5 percent to 13 percent between October 2010 and April 2011 to stem the effects of capital inflows on credit growth. Reserve requirements were then reduced to about 10 percent by the end of 2011 .

More broadly, the experiences of emerging market and advanced economies with macroprudential policies suggest that they are effective at reducing financial vulnerabilities. Combining several macroprudential measures (countercyclical capital requirements, dynamic loan-loss provisioning, sector-specific credit growth limits, and time-varying caps on loan-tovalue or debt-to-income ratios) in 57 advanced and emerging economies from 2000 to 2013 , Akinci and Olmstead-Rumsey (2015) find that they have a significant effect on bank credit growth, housing credit growth, and house price inflation, even after controlling for monetary policy changes, which at times accompany changes in macroprudential policies. In addition, policies targeted to a specific sector, for instance housing-related policies, tend to be more effective. Importantly, macroprudential policies can be targeted more precisely to ensure greater resilience in credit allocation, which a broader tool like monetary policy cannot do. Several other papers have also found macroprudential policies to be effective at reducing the procyclicality of credit growth (see, e.g., Lim et al., 2011, Kuttner and Shim, 2013, Claessens et al., 2014, and Cerutti et al., 2017, among others).

Nonetheless, while the evidence suggests that macroprudential policies are effective in reducing financial vulnerabilities, we still lack clarity on the strength of these tools. This is because most studies only capture the use of macroprudential policies, without accounting for their intensity 
(e.g., macroprudential policies are simply captured by qualitative dummy variables). This partly reflects the fact that we still know little about how much "leakage" these policies suffer from, that is, how much the macroprudential policies shift financing activities to institutions not impacted by the regulations. However, regardless of the actual amount of leakage, it is not sufficient to render the policies ineffective, since the studies detect significant effects. Overall, countries need to experiment with calibrating these tools gradually to achieve the desired outcomes.

Moreover, although macroprudential tools may be available and effective at reducing financial vulnerabilities, any enthusiasm about these tools must be balanced against relevant concerns about the governance structure of macroprudential tools and inaction biases. As documented by Edge and Liang (2019), in the wake of the financial crisis, several economies have introduced multiagency financial system committees (FSCs) to address financial stability risks. Importantly, they also report that no countries established a new agency with a specific financial stability mandate and with appropriate macroprudential tools. Instead, their evidence suggests that FSCs are established to facilitate information sharing, communication, or policy coordination across agencies. Their analysis also documents an important role for the political sector in the conduct of macroprudential policies, with FSCs typically being led by the ministry of finance. Such a structure acknowledges the important direct distributional impacts of macroprudential policy, although it may come at the cost of policy inertia when policy actions would also entail political costs (see also Jenkins and Longworth, 2015, for a Canadian perspective). Hence, absent better governance, monetary policymakers will need to remain vigilant to the evolution of financial stability risks.

\section{Where Does That Leave Us?}

Looking at the evidence from advanced and emerging market economics, much uncertainty still remains regarding the effectiveness of monetary and macroprudential policies in managing the financial cycle. Whether policymakers choose to use monetary policy or different forms of macroprudential policies to help financial stability, calibrating those responses will be highly uncertain. Policymakers will thus need to be pragmatic and gradual in their approach and be ready to update their policy strategy as they gather new evidence. Still, the international evidence suggests that targeted macroprudential policies offer a more promising avenue. In particular, a 
miscalibrated macroprudential response that tightens credit conditions in a specific market too much will have a more contained negative impact on the economy than would be the case if a monetary policy stance were too tight.

One difficulty that central bankers in many countries will continue to face is that they do not control macroprudential tools and can often only provide guidance within an advisory body. However, in contrast to most other agencies, central banks have the necessary macroeconomic and financial expertise and an economy-wide perspective that they can use to influence macroprudential decisions. This approach has worked relatively well in Canada recently with the adoption of several policies that have brought about a more resilient allocation of credit. However, inaction biases are still inherently present and could arise in the future. Designing a governance structure that would mitigate them would be a step in the right direction. 


\section{References}

Adrian, T., Duarte, F., Liang, N., and P. Zabczyk, (2019). "Monetary and macroprudential policy with endogenous risk," manuscript.

Akinci, O. and J. Olmstead-Rumsey, (2015). "How effective are macroprudential policies? An empirical investigation," International Finance Discussion Papers Board of Governors of the Federal Reserve System 1136.

Bauer, G.H. and E. Granziera, (2017). "Monetary policy, private debt, and financial stability risks, International Journal of Central Banking, vol. 13, 337-373.

Beaudry, P., (2020). "Monetary policy and financial vulnerabilities," remarks at Université Laval, Québec, Québec, January 30, 2020.

Borio, C., Furfine, C., and P. Lowe, (2001). "Procyclicality of the financial system and financial stability: issues and policy options" in Marrying the Macro- and Micro-prudential Dimensions of Financial Stability, BIS Papers, No 1, pp 1-57.

Borio, C. and P. Lowe, (2002). “Asset prices, financial and monetary stability: exploring the nexus," BIS Working Paper No. 114.

Bruno, V. and H. S. Shin, (2015). "Capital flows and the risk-taking channel of monetary policy," Journal of Monetary Economics, vol. 71, 119-132.

Cerutti, E., S. Claessens, and L. Laeven, (2017). "The use and effectiveness of macroprudential policies: New evidence.” Journal of Financial Stability, vol. 28, 203-224.

Claessens, S., Ghosh, S. R., Mihet, R., (2014). "Macro-Prudential Policies to Mitigate Financial System Vulnerabilities,” IMF Working Papers 14/155, International Monetary Fund.

Corsetti G., Dedola L., and S. Leduc, (2010). "Optimal monetary policy in open economies," in Benjamin Friedman and Michael Woodford, Handbook of Monetary Economics, Vol. 3B, pp. $861-934$.

Corsetti, G., Dedola, L., and S. Leduc, (2020). "Exchange rate misalignment and external imbalances: What is the optimal monetary policy response?" Federal Reserve Bank of San Francisco Working Paper 2020-04. 
Crockett, A., (2000). "Marrying the micro- and macro-prudential dimensions of financial stability," BIS Review No 76.

Curdia, V. and Woodford, M. (2016). "Credit frictions and optimal monetary policy," Journal of Monetary Economics, vol. 84, pp. 30-65.

Drehmann, M., Borio, C., and K. Tsatsaronis, (2012). "Characterising the financial cycle: don't lose sight of the medium term," BIS Working paper 380.

Edge, R. M. and N. Liang, (2017). "New financial stability governance structures and central banks," Hutchins Center Working Paper \#32.

Farhi, E., and I. Werning, (2016). "A theory of macroprudential policies in the presence of nominal rigidities." Econometrica 84 (5): 1645-1704.

Federico, P., Vegh, C.A. and Vuletin, G. (2012). "Reserve requirement policy over the business cycle," manuscript, University of Maryland.

Filardo, A., and P. Rungcharoenkitkul, (2016). "Quantitative case for leaning against the wind," BIS Working Paper No. 594, Bank for International Settlements.

Gerdrup, K. R., Hansen, F., Krogh Z. and J. Mai, (2017). "Leaning against the wind when credit bites," International Journal of Central Banking, vol. 13, 287-320.

Glick, R. and S. Leduc, (2012). "Central bank announcements of asset purchases and the impact on global financial and commodity markets," Journal of International Money and Finance, vol. $31,2078-2101$

Glick, R. and S. Leduc, (2018). "Unconventional monetary policy and the dollar: Conventional signs, unconventional magnitudes," International Journal of Central Banking, vol. 14, pp. 103152.

Gourinchas, P.O. and M. Obstfeld, (2012). "Stories of the twentieth century for the twenty-first," American Economic Journal: Macroeconomics 4 (1), 226-65.

Gourio, F., Kashyap, A.K., and J.W. Sim, (2018). "The trade-offs in leaning against the wind," IMF Economic Review, vol. 66, 70-115. 
Jenkins, P. and D. Longworth, (2015). "Securing monetary and financial stability: Why Canada needs a macroprudential policy framework," C.D. Howe Institute Commentary, C.D. Howe Institute, issue 429, June.

Jordà, Ò., Schularick, M. and A. M. Taylor, (2015). “Mortgaging the Future?” Federal Reserve Bank of San Francisco Economic Letter 2015-09.

Kiley, Michael, (2018). "What macroeconomic conditions lead financial crises?” Finance and Economics Discussion Series 2018-038. Washington: Board of Governors of the Federal Reserve System.

Juselius, M., Borio, C., Disyatat, P., and M. Drehmann, (2016). "Monetary policy, the financial cycle, and ultra-low interest rates," BIS Working Paper No. 569, Bank for International Settlements.

Kuttner, K., and I. Shim, 2013. “Can Non-Interest Rate Policies Stabilize Housing Markets? Evidence from a Panel of 57 Economies.” NBER Working Paper 19723.

Leduc, S. and J.-M. Natal, (2016). "Monetary and macroprudential policy in a leveraged economy," Economic Journal, v. 128, pp. 797-826.

Lim, C. H., Costa, A., Columba, F., Kongsamut, P., Otani, A., Saiyid, M., Wezel, T., Wu, X., (2011). "Macroprudential Policy: What Instruments and How to Use Them? Lessons from Country Experiences,” IMF Working Papers 11/238, International Monetary Fund.

Mason, J.W. and A. Jayadev, (2014). "Fisher dynamics in US household debt, 1929-2011," American Economic Journal: Macroeconomics 6, 214-234.

Mimi, Y., Sunel, E., and T. Taşkın, (2013), "Required reserves as a credit policy tool," The B.E. Journal of Macroeconomics, vol. 13, 823-880.

Montoro, C. and R. Moreno, (2011). "The use of reserve requirements as a policy instrument in Latin America," BIS Quarterly Review, 53-65.

Musso, A., Neri, S., and L. Stracca, (2017). "Housing, consumption and monetary policy: How different are the U.S. and the euro area?” Journal of Banking and Finance, vol. 35, 3019-41. 
Neely, C., (2015). "Unconventional monetary policy had large international effects," Journal of Banking and Finance 52, 101-111.

Obstfeld, M. and K. Rogoff, (2010). "Global imbalances and the financial crisis: Products of common causes," Asia and the Global Financial Crisis, Asia Economic Policy Conference, Federal Reserve Bank of San Francisco, pp. 131-172.

Pereira da Silva, L. A., (2013). "From currency wars to policy peace under the G-20," Remarks at the Peterson Institute for International Economics.

Rajan, R., (2014). “Competitive monetary easing - is it yesterday once more?” Remarks at the Brookings Institution, Washington DC, 10 April 2014.

Rogers, J.H., Scotti, C. and J.H. Wright, (2018). "Unconventional monetary policy and international risk premia," Journal of Money, Credit, and Banking, vol. 50, no. 8, pp. 1827-1850.

Schularick, M. and A. M. Taylor, (2012). 'Credit booms gone bust: monetary policy, leverage cycles, and financial crises 1870-2008," American Economic Review, vol. 102(2), pp. 1029-61.

Smets, F., (2014). "Financial stability and monetary policy: How closely interlinked?"

International Journal of Central Banking, vol. 10, 263-300.

Svensson, L., (2017). "Cost-benefit analysis of leaning against the wind," Journal of Monetary Economics, vol. 90, 193-213.

Vegh, C. A. and G. Vuleting, (2012). "Reserve requirements over the business cycle," NBER Working Paper No. 20612.

Walsh, C. E., (2017). "Dicussion of 'Leaning against the wind when credit bites,"' International Journal of Central Banking, vol. 13, 321-336.

Woodford, Michael, (2012). "Inflation targeting and financial stability," Sveriges Riksbank Economic Review, vol. 1, pp. 7-32. 